\title{
Determining if a Change to a Proposal Requires Additional NEPA Documentation: The Smithsonian Solution
}

Prepared for the U.S. Department of Energy Contract DE-AC06-96RL13200

FLUOR DANIEL MANFORD, INC. Richland, Washington

Hanford Management and Integration Contractor for the U.S. Department of Energy under Contract DE-AC06-96RL13200

Copyright Llcense By acceptance of this article, the publisher and/or recipient acknowledges the U.S. Government's right to retain a nonexclusive, toyalty-free license in and to any copyright covering this paper. 


\section{INFORMATION CLEARANCE FORM}

A. Information Category

\begin{tabular}{ll}
$\square$ Abstract & $\square$ Joumal Article \\
$\square$ summary & $\square$ Internet \\
$\square$ Visual Aid & $\square$ Software \\
$\square$ Full Paper & $\square$ Report \\
$\square$ Other & \\
\hline
\end{tabular}

8. Document Number HNF-3242-FP

C. Titlo

Determining if a Change to a Proposal Requires Additional NEPA Documentation: The Smithsonian Solution

D. Intemet Address

E. Roquired Information

1. Is document potentially classified? $\mathrm{X}$ No $\square$ Yes (MANDATORY)

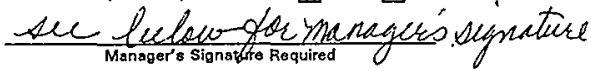

4. Does Information Contain the Following: (MANDATORY)

s. Now or Novel (Patentablel subject Matter? $\square$ No $\square$ Yes If "Yes", Disclosure No.:

b. Information Received in Confidence, Such as Proprietary and/or Inventions? X No $\square$ Yos if "Yos", Affix Appropriate Legends/Notices.

c. Copyrights? $\square$ No $\square$ Yes If "Yes", Attach Permission. .

d. Trademarks? $\square$ No $\square$ Yes If "Yes", Identify in Document.

5. Is information requiring submission to OSTI? $\square$ No $\mathbb{Q}$ Tes If Yes UC-2000 and B\&R-EW7070100

6. Release Level? $\square$ Public $\square$ Limited

7. Charge Code R1A62. HN97036\%

3. References in the Information are Applied Tochnology Export Controlled information

i. Titio of Joumal environmental journal

G. Complete for a Presentation

1. Title for Conference or Meeting N/A

2. Group Sponsoring $N / A$

3. Dato of Conference $N / A$

5. Will Information be Published in Proceedings? $\mathrm{X}$ No $\square$ Yes

4. City/State $N / A$

H. Author/Requestor

C. H. Eccleston (Print and Sign)

1. Roviewers

General Counsel

Office of Extemat Aftairs

DOE-RL

6. Will Material be Handed Out?

四 $\square^{\text {Yes }}$

A. G. Weiner fOSpur (Print and Sign)

$8 / 19 / 90$

Signature

Public Y/N (If N, complete J)

Other

If

Signature

(Y) $\mathrm{N}$

J. If Information Includes Sensitive Information and is not to be released to the Public indicate category below.
$\square$ Applied Technology
$\square$ Protected CRADA
$\square$ Personal/Private
$\square$ Export Controlled
$\square$ Propriatary
$\square$ Procurement-Sensitive
$\square$ Business-Sensitivo
$\square$ Patentabio
$\square$ Prodecisional
$\square$ other (spocify)

$\square$ UCN!

K. If Additional Comments, Plesse Attach Separato Sheet

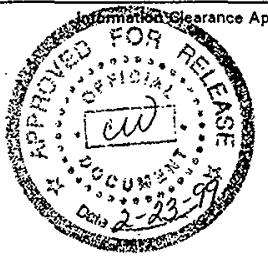




\title{
Determining if a Change to a Proposal Requires Additional NEPA Documentation: The Smithsonian Solution
}

\author{
C. H. Eccleston
}

Waste Management Federal Services Hanford

Date Published

September 1998

To Be Published in

Journal of Environmental Quality Management

Prepared for the U.S. Department of Energy Contract DE-AC06-96RL13200

FUOR DANALL HANFORD, INC.

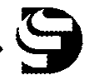

P.O. Box 1000

Richland, Washington

Hanford Management and Integration Contractor for the

U.S. Department of Energy under Contract DE-AC06-96RL13200

Copyright License By acceptance of this article, the publisher and/or recipient acknowledges the U.S. Government's right to retain a nonexclusive, royalty-free license in and to any copyright covering this paper. 


\section{LEGAL DISCLAMER}

This report was prepared as an account of work sponsored by an agency of the United States Government. Neither the United States Government nor any agency thereof, nor any of their employees, nor any of their contractors, subcontractors or their employees, makes any warranty, express or implied, or assumes any legal liability or responsibility for the accuracy, completeness, or any third party's use or the results of such use of any information, apparatus, product, or process disclosed, or represents that its use would not infringe privately owned rights. Reference herein to any specific commercial product, process, or service by trade name, trademark, manufacturer, or otherwise, does not necessarily constitute or imply its endorsement, recommendation, or favoring by the United States Government or any egency thereof or its contractors or subcontractors. The views and opinions of authors expressed herein do not necessarily state or reflect those of the United States Government or any agency thereof.

This report has been reproduced from the best available copy.

Printed in the United States of Americe

DISCLM-2.CHP (1-91) 


\title{
DETERMINING IF A CHANGE TO A PROPOSAL REQUIRES ADDITIONAL NEPA DOCUMENTATION
}

\author{
THE SMITHSONIAN SOLUTION
}

\author{
C. H. ECCLESTON
}

\begin{abstract}
Proposed actions tend to evolve over time. Once National Environmental Policy Act (NEPA) documentation is completed, agencies are at risk that subsequent changes may not be adequately covered or that existing NEPA documentation may be completely invalidated. Neither NEPA nor its subsequent regulations provide sufficient direction for determining the degree to which a proposed action may change before preparation of new or supplemental documentation is necessary. Yet, decisionmakers are routinely involved in determining if a change to a proposed action departs, to such an extent, from the description presented in the NEPA document that additional documentation is necessary. Experience demonstrates that no two decisionmakers will completely agree; one decisionmaker might believe that a particular change would not require additional documentation, while the other concludes the exact opposite.

Lacking definitive direction, decisionmakers and critics alike may point to a universe of potential considerations as the basis for defending their claim that a change in an action does or does not require new or additional NEPA documentation. Assertions are often based on equivocal opinions that can be neither proved nor disproved. Moreover, decisionmakers are frequently placed in an arduous dilemrna of justifying a decision, for which there is no generally accepted methodology on which to base the decision.
\end{abstract}

Lack of definitive direction can prolong the dccisionmaking process, resulting in project delays. This can also lead to inappropriate levels of NEPA documentation, inconsistencies in decisionmaking, and increased risk of a legal challenge because of insufficient documentation. Clearly, a more systematic and less subjective approach is needed. A tool for streamlining the NEPA process, by reducing this degree of subjectivity, is presented in this paper.

In June of 1995, a question was raised in the morning session of the National Association of Environmental Professionals' (NAEP) annual conference in Washington D.C. Specifically: "To what degree can an action be changed before the corresponding description in the National Environmental Policy Act (NEPA) documentation must be revised to provide sufficient coverage 
for the action? This is a classical paradox, of which most NEPA practitioners are all too familiar. At the conclusion of the session, I was gazing out along the Potomac River when I began reflecting on this problem; not surprisingly, I refer to this problem as the Potomac Paradox. The Potomac Paradox is one of the most ambiguous and time consuming problems confronting most NEPA practitioners and decisionmaking.

\section{THE PROBLEM}

NEPA was established by Congress to ensure that environmental factors are properly considered during the early planning process, before federal agencies make a final decision to proceed with a proposed action.' Yet, by its very nature, planning tends to be a dynamic, evolving process. A final design or plan often deviates, at least slightly, from the description and analysis presented in the NEPA document prepared earlier. Neither NEPA nor its subsequent NEPA implementing regulations provide definitive direction for determining:

The degree to which a proposed action may change from the action described in the NEPA documentation before the action is no longer adequately covered, and a new analysis must be prepared. ${ }^{2}$

Experience indicates that no two decisionmakers are likely to completely agree on the degree to which an action could vary before it is no longer covered or the existing NEPA documentation is invalidated. Lacking a consistent methodology for reaching such decisions, the courts may ultimately be the avenue of last resort.

Later, while strolling through the courtyard of the Smithsonian Museum, I pondered potential resolutions to this dilemma. What should a decisionmaker consider in reaching such a determination? Slowly, potential decisionmaking criteria came into focus. One by one, nearby buildings were closing as I looked for a room with a table on which to scrawl some thoughts into my organizer. Only the Smithsonian cafeteria remained opened. I walked into the cafeteria, found an empty table, and went to work scribbling potential criteria that came to mind. For obvious reasons, the proposed decisionmaking tool for resolving the Potomac Paradox is referred to as the Smithsonian Solution."

\section{RLUSTRATING THE PROBLEM}

Suppose an Environmental Impact Statement (EIS) is prepared for a proposed action involving construction and operation of an electrical power plant. The proposed action involves three stoker coal-fired generators, each capable of producing 100 megawatts (MW) of electric energy.

* The concepts advanced in this paper are strictly those of the author and do not reflect opinions of the Smithsonian Institution. 
Together the three boilers would produce a total of $300 \mathrm{MW}$. A water supply line, consisting of two pipelines, would be constructed from a nearby lake to transmit cooling water to the plant. On completing the EIS, the agency issues a Record of Decision (ROD) to pursue the proposed action.

After the ROD is issued, budgetary and other considerations require that certain design changes be made to the original concept. The new design consists of four $80 \mathrm{MW}$ boilers using technology that is similar, but varies slightly, from the design presented in the EIS. The new plant design also involves construction of a backup pipeline that would run approximately 300 feet adjacent to the two pipelines described in the EIS.

The new concept would result in environmental impacts that are marginally different from those presented in the EIS. As a result of the new design, air quality impacts, resulting from sulfur and nitrogen oxide emissions, would be approximately $5 \%$ less than those presented in the EIS. However, particulate impacts would be approximately $7 \%$ higher. The new plant design would also increase cooling water requirements by $12 \%$.

Can such variations be considered trivial enough that supplementing the EIS is not necessary? What criteria can a decisionmaker use as the basis for reaching a determination? Clearly, a systematic and rigorous methodology is needed to assist decisionmakers in making such determinations. A decisionmaking tool for making such determinations follows. Emphasis has been placed on developing a tool that fulfills the fundamental intent of NEPA and meets specific requirements provided in the Council on Environmental Quality's (CEQ) NEPA implementing regulations.

\section{PROFESSIONAL VIEWS VARY WIDELY}

There are many schools of thought regarding the Potomac Paradox. Professional views vary widely, often reflecting an individual's professional experience, responsibility, personal bias, and technical training. At one end, a school of thought holds that substantial changes can be made to a proposed action without invalidating the NEPA coverage, so long as the impacts do not 'substantially' exceed projections presented within the NEPA document. At the opposite end of the continuum, some professionals maintain that no deviation from the description presented in the NEPA document is permissible; any variation from the description presented in the NEPA documentation would require preparation of additional NEPA documentation. Most views fall somewhere between these opposite ends of the spectrum.

As a rigorous decisionmaking tool has not previously been available, decisionmakers are often left with only subjective factors on which to base a final determination. Decisionmakers and critics alike may point to a universe of potential factors as evidence for substantiating a particular position; thus, assertions are frequently based on vague or ambiguous opinions that can neither be proved nor disproved. Proponents, for example, might argue that a certain design change is relatively minor and can be made under the existing NEPA documentation, while critics might 
argue the exact opposite. If an agency decides that new NEPA documentation is not necessary, critics may claim that the decision is based on arbitrary considerations or was politically motivated.

Lack of a definitive methodology can slow the decisionmaking process resulting in project delays, lead to inconsistencies in the review of NEPA documents, and can increase the risk that a project may be challenged as a consequence of inadequate NEPA analysis. While common sense is an integral part of decisionmaking, a systematic methodology would greatly reduce the degree of ambiguity and subjectivity that currently exists.

\section{PROCEDURAL MECHANISMS HAVE NOT ELIMINATED THE DILEMMA}

Some agencies have attempted to address the Potomac Paradox by adopting formal processes for determining when a change requires additional NEPA analysis. For example, the U.S. Department of Energy (DOE) has established a general mechanism for making such determinations. Under this mechanism, a document referred to as a Supplement Analysis (SA) is prepared to assist the DOE in making such determinations. ${ }^{3}$ Essentially, the SA compares a current project design with the original description presented in an EIS. Based on the results of this comparison, a decisionmaker determines if the proposal has changed to such a degree that a new or supplemental EIS is required.

While the SA process provides a formal mechanism to be followed in determining when an EIS must be supplemented, the process does not resolve the Potomac Paradox, as decisionmakers are still faced with the dilemma of making determinations based largely on subjective opinions. Moreover, use of the SA is restricted to the domain of determining if a supplemental EIS must be prepared to address a change. The reader should note that a similar DOE provision does not exist for making determinations that do not involve an existing EIS (i.e., reviewing an Environmental Assessment [EA] or categorical exclusion). In developing a systematic and defensible tool for addressing whether an EIS must be prepared, one might best begin by asking two fundamental questions:

- What is the fundamental intent and purpose of NEPA?

- What would be gained by preparing additional NEPA documentation?

The answer to the first question is important, because no tool will work unless it fulfills the underlying purpose and intent of NEPA. As expressed in the CEQ NEPA regulations, the underlying intent and purpose of NEPA is "... to help public officials make decisions that are based on an understanding of environmental consequences..." ${ }^{14}$ Moreover, agencies are required to prepare NEPA documents that "concentrate on issues that are truly significant to the action in question, rather than amassing needless detail." ${ }^{5}$ Furthermore, this environmental information must be made available to "public officials and citizens before decisions are made and before 
actions are taken." ${ }^{16}$ Thus, these regulatory requirements address the first question and therefore provide a starting point for developing a tool that aids the decisionmaker.

The answer to the second question is equally important. Because the purpose of NEPA is to provide decisionmakers with environmental information useful in reaching decisions, there appears to be no justification for preparing additional documentation unless the information would contribute value to the decisionmaking process. The answers to both questions provide a starting point for developing the decisionmaking tool that follows.

\section{THE SMITHSONIAN SOLUTION: A BASIS FOR A RATIONAL AND DEFENSIBLE TOOL}

The purpose of NEPA is to consider the impact of proposed (i.e., 'new') actions. Under the Smithsonian Solution, the proposed change is reviewed against the existing NEPA document for the project or action. If the proposed change is a 'new' action not previously considered, the requirement to prepare additional NEPA documentation is automatically triggered.

If the issue in question is not a 'new' action but represents a change in the description of the previously considered action/impacts (including new information or circumstances), the decisionmaker complies with requirements prescribed in 40 Code of Federal Regulations (CFR) $1502.9[\mathrm{c}][1]$. Specifically, this provision states that an EIS must be supplemented if:

(i) The agency makes substantial changes in the proposed action that are relevant to environmental concerns; or

(ii) There are significant new circumstances or information relevant to environmental concerns and bearing on the proposed action or its impacts.

Because any action is potentially subject to the requirements of an EIS until proven otherwise, this provision can be considered equally applicable to actions that do not necessarily involve an EIS. While $40 \mathrm{CFR} 1502.9$ [c] [1] provides general factors for determining if a change requires additional review, this provision fails to provide specific criteria for making such a determination. For example, what constitutes a "substantial change" and what does "significant new circumstances or information relevant to environmental concerns" mean? Criteria are proposed in the following section to assist the reader in evaluating the two factors specified in 40 CFR $1502.9[\mathrm{c}][1]$.

\section{EVALUATION CRITERIA FOR ASSESSING CHANGES}

This paper proposes five discrete criteria (numbered 1 through 5 in Table 1) to assist decisionmakers in determining if a change to a proposed action requires additional NEPA 
documentation. These criteria are based on the premise that no defensible model can be constructed unless the model fulfills the purpose and intent of NEPA. A thorough legal review of over 200 NEPA cases involving supplemental EISs was performed in constructing the following tool for resolving the Potomac Paradox. These five criteria were found to be consistent with existing case law.

\section{Table 1. Criteria for Determining When a Change to an Action Requires Preparation of Additional NEPA Documentation.}

1. There is a change in a previously described action that might result in a significant new impact not previously investigated in the earlier NEPA document.

2. There is a change in a previously described action that might cause an analyzed impact to deviate significantly from projections described in the existing NEPA document (i.e., there is a reasonable possibility that the proposed change could significantly alter impact projections investigated earlier).

3. There is a reasonable expectation that new alternative(s) could be identified for achieving the purpose and need of the proposed change, which was not alveady considered in the existing NEPA document, and might affect the environment in a manner substantially different from the environmental effects of the proposed change.

4. Significant new circumstances or information relevant to environmental concerns has been obtained that could substantially change the agency's decision or could allow the public to contribute comments that could substantially improve or affect the manner in which the proposed change to an action is implemented.

5. Significant new circumstances or information relevant to environmental concerns has been obtained that could substantially change the public's understanding (or acceptance/rejection) of the proposed change, in a manner substantially different from that which existed when the NEPA document was prepared. The public would benefit from an additional NEPA process.

\section{TECHNICAL BASIS FOR THE CRITERIA USED IN THIS TOOL}

The technical basis for each criterion cited in Table 1 is described in the following sections. Criteria 1 and 2 are specifically designed to allow a decisionmaker to evaluate the factor described earlier in 40 CFR $1502.9[\mathrm{c}][1][i]$. Similarly, criteria 3, 4, and 5 provide decisionmakers with specific criteria for evaluating 40 CFR $1502.9[\mathrm{c}][1]$ [ii]. As described shortly, it would be difficult to justify why additional NEPA documentation (i.e., EIS or other NEPA document) would be required if at least one of the following five criteria is not triggered. Each of the five criteria are described in more detail in the following sections. 


\section{CRITERION 1}

NEPA and its requirement to perform an impact analysis pivots on the concept of significance. Accordingly, the first criterion is based on the definition of significance as defined in $40 \mathrm{CFR}$ 1508.27. The NEPA regulations state that significance must be assessed in terms of both the context and intensity of the impact (Table 2). ${ }^{7}$ As indicated in Table 2 , ten intensity factors are prescribed for assessing significance in terms of the intensity of an impact.

The term major as used in the regulatory provision to prepare an EIS on all "... major federal actions significantly affecting the quality of the human environment," reinforce, but not to have a meaning independent of the term significantly." This interpretation follows from the premise that it is not the size of an action but the significance of its impact(s) that is of concern in NEPA. Consistent with this interpretation, Criterion 1 interprets the phrase "substantial changes in the proposed action" (as used in 40 CFR 1502.9[c][1][i]) to be equivalent to the phrase "significant impacts." Thus, the first criterion in Table 1 incorporates use of the terms "change" in lieu of "substantial changes" and "significant impact" instead of "environmental concerns."

If it appears that newly identified impacts might potentially be significant, the appropriate level of NEPA documentation is prepared (e.g., EA or EIS); in reaching a conclusion regarding its significance, the new impact is then evaluated in terms of regulatory factors described in $40 \mathrm{CFR}$ 1508.27 (Table 2).

\section{CRITERION 2}

Using an approach similar to that described for Criterion 1, additional NEPA documentation is warranted if there is a reasonable chance that the proposed change could cause a previously identified impact to deviate significantly from projections presented in the existing NEPA analysis. If a determination is made that the previously identified impacts might deviate substantially, the appropriate level of NEPA documentation is prepared and the significance factors described in Table 2 are used in reaching a conclusion regarding significance.

Under this criterion, a change in a previously identified impact is viewed in terms of the degree to which this impact departs from the projections presented in the NEPA analysis, based on the factors cited in $40 \mathrm{CFR} 1508.27$. This procedure is explained in more detail in the following section. 


\section{Table 2. The Term "Significantly" as Defined in 40 CFR 1508.27 Requires Consideration of Context and Ten Intensity Factors.}

(a) Context. This means that the significance of an action must be analyzed in several contexts such as society as a whole (human, national), the affected region, the affected interests, and the locality. Significance varies with the setting of the proposed action. For instance, in the case of a site-specific action, significance would usually depend upon the effects in the locale rather than in the world as a whole. Both short- and long-term effects are relevant.

(b) Intensity. This refers to the severity of impact. Responsible officials must bear in mind that more than one agency may make decisions about partial aspects of a major action. The following should be considered in evaluating intensity:

(1) Irapacts that may be both beneficial and adverse. A significant effect may exist even if the Federal agency believes that on balance the effect will be beneficial.

(2) The degree to which the proposed action affects public health or safety.

(3) Unique characteristics of the geographic area such as proximity to historic or cultural resources, park lands, prime farmlands, wetlands, wild and scenic rivers, or ecologically critical areas.

(4) The degree to which the effects on the quality of the human environment are likely to be highly controversial.

(5) The degree to which the possible effects on the human environment are highly uncertain or involve unique or unknown risks.

(6) The degree to which the action may establish a precedent for future actions with significant effects or represents a decision in principle about a future consideration.

(7) Whether the action is related to other actions with individually insignificant but cumulatively significant impacts. Significance exists if it is reasonable to anticipate a cumulatively significant impact on the environment. Significance cannot be avoided by terming an action temporary or by breaking it down into small component parts.

(8) The degree to which the action may adversely affect districts, sites, highways, structures, or objects listed in or eligible for listing in the National Register of Historic Places or may cause loss or destruction of significant scientific, cultural, or historical resources.

(9) The degree to which the action may adversely affect an endangered or threatened species or its habitat that has been detennined to be critical under the Endangered Species Act of 1973

(10) Whether the action threatens a violation of Federal, State, or local law or tequirements imposed for the protection of the environment. 


\section{The Significant Departure Doctrine}

Criterion 2 requires special explanation. As described earlier, judgments regarding the significance of an impact involve consideration of both the context as well as ten intensity factors (Table 2). While the CEQ NEPA regulations provide factors for use in determining significance, they do not provide specific direction on how these factors are to be interpreted or considered. The NEPA regulations grant agencies wide latitude in interpreting and assessing the significance of environmental impacts. For example, in several cases the NEPA regulations state that decisionmakers should consider the degree to which certain significance factors may effect the environment. ${ }^{10}$ The NEPA Regulations, however, do not state how these factors are to be assessed - only that agencies are to consider the degree to which these might effect the environment. Ultimately, responsibility has been left to the discretion of the individual agencies in determining how the significance factors are to be considered.

Normally, CEQ's significance factors are used in determining if an action would affect the environment to such an extent that an EIS is required. Under the proposed methodology, CEQ's significance factors are used in a similar but slightly different manner. With respect to Criterion 2 , this paper proposes that a decisionmaker consider the significance factors from the standpoint of determining if the impacts associated with a proposed change could:

diverge from the original analysis to such a degree as to constitute a significant departure (i.e., deviate significantly) from the earlier impact projection, thus triggering the need to prepare additional NEPA documentation.

Accordingly, impacts associated with a change in an action would be considered inconsequential if these effects do not depart from projections presented in the original NEPA document to such an extent that the change effectively constitutes a significant 'new' impact, not already addressed. Conversely, additional NEPA documentation (e.e., EA or EIS) would be warranted if a proposed change could cause an impact to deviate from the original analysis to such an extent as to constitute a significant 'new' impact, not previously addressed. Thus, with respect to Criterion 2 , significance is interpreted essentially from a relative standpoint as opposed to a more standard interpretation that views significance from an absolute perspective.

\section{CRITERION 3}

The third criterion is based on the fact that an analysis of alternatives is the "heart" of an EIS. ${ }^{\text {" In }}$ certain instances, a change to an action may be considered a new action where a reasonable alternative(s) exists for implementing the proposed change. Hence, additional NEPA documentation may be justified to investigate the impacts of alternative means for meeting the proposed change. Specifically, additional analysis is warranted if a reasonable alternative(s) exists for implementing the proposed change that: 
- Could affect the environment in a manner substantially different from the environmental effects of the proposed change and,

- Has not already been considered in a NEPA document prepared for the proposed action.

These two conditions are justified on the basis that an analysis of an alternative to a proposed change is necessary if it is reasonable to believe that this review could identify impacts substantially different from those associated with the proposed change in the action. For instance, if an agency desires to change the type of air control exhauster discussed in the NEPA document, an analysis of alternative types of air pollution exhausters would normally not be warranted unless alternative types of exhausters might result in substantially different environmental impacts; additional NEPA documentation, however, would be justified if such an analysis would assist the decisionmaker in making a more informed decision regarding the implementation of the proposed change.

\section{CRITERION 4}

The fourth criterion is based on the fact that NEPA is a "public" planning and decisionmaking process. ${ }^{12}$ Additional NEPA analysis is justified if significant new circumstances or information comes to light that could substantially affect either the agency's decision or the public's ability to review and contribute substantial comments on the proposed change. For example, additional documentation is warranted if it is reasonable to believe that public review of the proposed change could allow another agency or a member of the public to contribute comments that could substantially reduce impacts associated with the proposed change.

\section{CRITERION 5}

As described in the fourth criterion, NEPA is a "public" process. An additional NEPA analysis is justified if new circumstances or information comes to light that could substantially change the public's understanding of the proposed change in a manner that is substantially different from the situation that existed during the earlier NEPA process. This criterion is premised on the requirement that the public has a right to be informed concerning federal actions or substantial changes to federal actions. 


\section{THE SMITHSONIAN SOLUTION: A TOOL FOR DETERMINING WHEN A CHANGE REQUIRES NEPA DOCUMENTATION}

Figure 1 provides a general purpose tool, consisting of six discrete tests (diamond figures) for determining when a proposed change requires additional NEPA documentation. This tool (Smithsonian-Solntion Tool) summarizes the criteria depicted in Table 1. The tool does not promote any degree of decisionmaking beyond the level already exercised in reviewing such problems. To the contrary, the tool provides decisionmakers with a systematic, rigorous, consistent, and defensible set of tests for performing what has otherwise been a relatively subjective decisionmaking process.

The criteria presented in Table I may also be useful in scoping an SA (or other NEPA review document) to review the change and determine if additional NEPA documentation is required; Once an SA has been prepared, these criteria can then be used to determine if the proposed change is significant enough warrant preparation of additional NEPA documentation.

The tool must be implemented on a case-by-case basis. Each test is evaluated according to the decisionmaker's best professional judgment. In responding to these tests, the decisionmaker considers the degree to which the intensity and context could be affected by the proposed change. Decisionmakers must also consider how the proposed change would effect cumulative impacts in addition to direct and indirect effects.

Use of this tool is not restricted to changes involving EISs; it can also be used (possibly with some minor modifications) to assist decisionmakers in reviewing a change to an EA. If the proposed change to the description/analysis presented in the EA is considered substantial, preparation of either a new EA or an EIS is warranted.

\section{APPLYING THE TOOL}

The tool is initiated with the first rectangle at the top of Figure 1. A proposed change is identified and then reviewed against the existing NEPA document. If the proposed change is a 'new' action not previously considered (refer to first diamond), the user automatically concludes that additional NEPA documentation must be prepared. If the proposed change involves a previously considered action, the action is reviewed in terms of the five remaining tests. The user is encouraged to refer back to the corresponding and more detailed criteria in Table 1.

The next three tests are considered with respect to the question, "Could additional NEPA analysis of the proposed change reveal:" All three tests (second, third, and fourth diamonds in Figure 1) are considered in determining the outcome of this question. A "Yes" to any one of the three tests is sufficient to reach a determination that additional NEPA documentation must be prepared. 
Identify a proposed change (and/or new information/circumstances).

Review this change against the existing NEPA documentation:

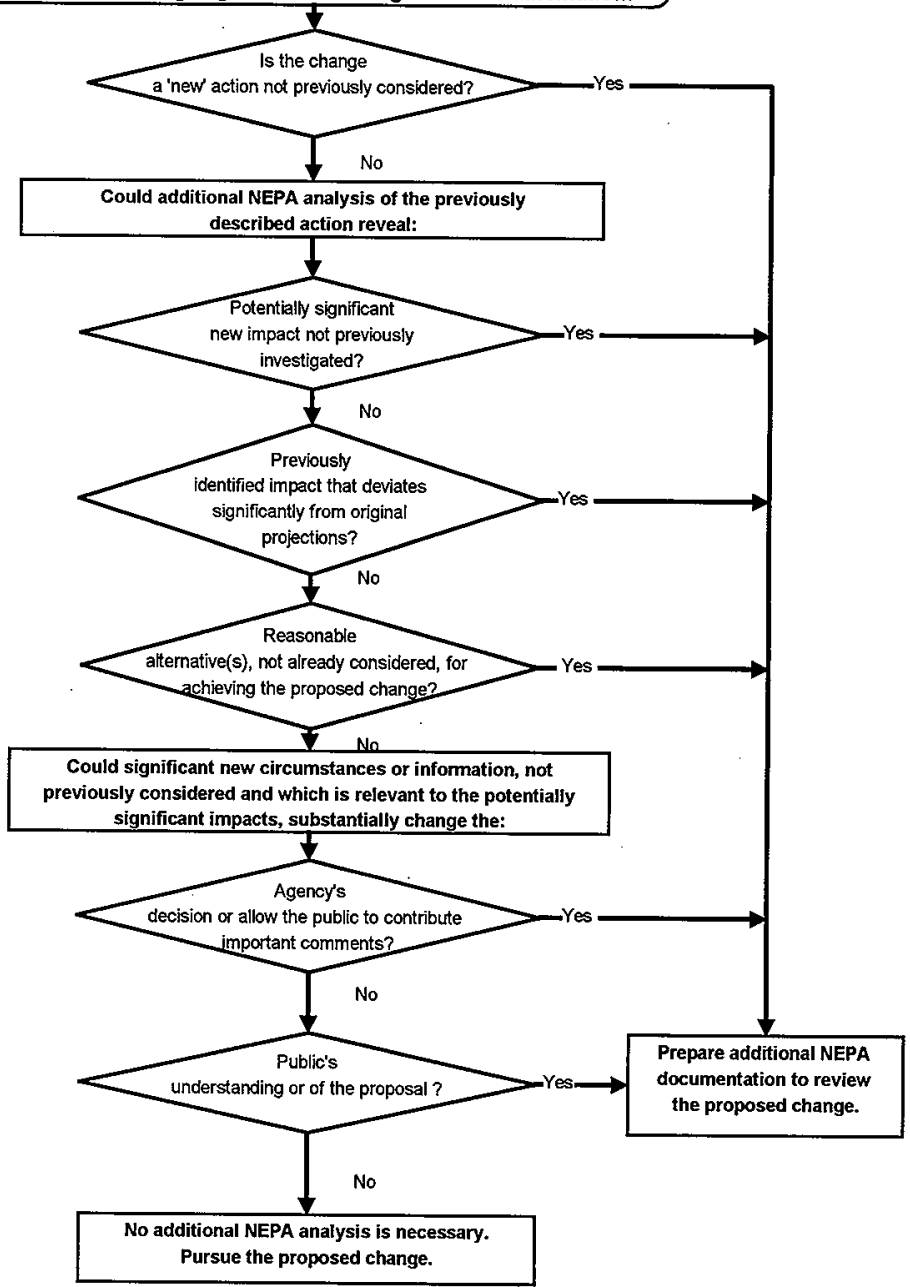

Figure 1. The Smithsonian-Solution Tool. The Tool Provides a Methodology for Determining when a Change Requires Additional NEPA Documentation. 
In a similar fashion, the remaining two tests are examined with respect to the question, "Could significant new circumstances or information, not previously considered and which is relevant to the potentially significant impacts, substantially change the:"

An answer of "No" to all of six tests supports a decision that the proposed change could be implemented without preparing additional NEPA documentation. A "Yes" answer to any one of the six tests provides a basis for concluding that additional NEPA documentation is necessary. Where the answer to any test is not clearly obvious, the user should error on the side of conservatism.

\section{ADVANTAGES, LMMITATIONS, AND RESTRICTIONS ON USE OF THE TOOL}

Admittedly, the Smithsonian Solution does not completely eliminate subjectivity. Decisionmaking by its very nature is subjective. Whereas the tool does not completely eliminate such subjectivity, the vast array of potential considerations are essentially reduced to six narrowly defined tests. Each test is evaluated according to the decisionmaker's best professional judgment. Views based on vague or ambiguous arguments are not justified. Be it a decisionmaker or citizen groups opposed to the project, one must be prepared to justify why the proposed change does or does not meet one or more of the tests. Opinions based on other criteria or arguments are considered irrelevant unless compelling justification can be made as to why additional factors should be considered.

While the Smithsonion Solution is applicable to a broad spectrum of agency actions encountered in addressing the Potomac Paradox, exceptions might arise that cannot be completely addressed with this tool. In such instances, additional factors might need to be considered before reaching a final decision. However, decisionmakers and critics alike would be expected to provide rational arguments and specific evidence justifying why additional factors beyond the six tests need to be considered.

\section{CONCLUSION}

Decisionmakers are routinely called on to determine if a proposed action varies to such an extent, from the description presented in the NEPA document, that additional NEPA analysis must be prepared. Until now, a systematic and consistent methodology for making such determinations has not existed. Lacking definitive direction, decisionmakers and critics alike might point to a universe of factors as the basis for defending a particular position. An inordinate amount of time and resources can be consumed reviewing these factors, slowing the decisionmaking process and increasing the risk of project delays.

While the Smithsonian Solution does not eliminate subjectivity completely, what has previously been a relatively ambiguous decisionmaking process is essentially narrowed to the domain of six specifically defined tests. This tool streamlines the NEPA process by providing a systematic 
approach for addressing the Potomac Paradox, thus reducing the time and resources required to make determinations while increasing the defensibility of the agency's determination.

The tool does not encourage any degree of decisionmaking beyond that already exercised routinely by agencies. Quite the contrary- decisionmakers are provided with a consistent, methodical, and defensible basis for reaching such determinations. If the status quo can be defended as falling within the domain of an agency's decisionmaking authority- surely a rigorous and systematic approach is equally, if not more, defensible. 


\section{ACKNOWLEDGMENTS}

I wish to thank Ms. B. D. Williamson (Fluor Daniel Hanford Inc, legal) who reviewed this paper and contributed to the legal research.

\section{REFERENCES}

1. The National Environmental Policy Act of 1969,42 U.S.C., Section 102

2. 40 Code of Federal Regulations (CFR) 1500-1508, "Regulations for Implementing the Procedural Provisions of the National Environmental Policy Act," Code of Federal Regulations, November 29, 1978.

3. 10 CFR 1021.314 (c), U.S. Department of Energy, National Environmental Policy Act; Implementing Procedures and Guidelines Revocation; Final Rule and Notice, April 24, 1992.

4. 40 CFR 1500.1 (c).

5. 40 CFR 1500.1(b).

6. 40 CFR 1500.1

7. 40 CFR 1508.27

8. 42 USC $\S 4332$, Sec. $102[\mathrm{c}]$.

9. 40 CFR 1508.18 .

10. 40 CFR 1508.27 (b) $(2,4,5,6,8)$

11. 40 CFR 1502.14 .

12. 40 CFR 1500.1 (b) and 1500.2 (d) 